\title{
Modeling of In-vehicle Magnetic refrigeration
}

Olsen, Ulrik Lund; Bahl, Christian; Engelbrecht, Kurt; Nielsen, Kaspar Kirstein; Tasaki, Y.; Takahashi, H.; Yasuda, Y.

\section{Published in:}

Proceedings of the fifth IIF-IIR International Conference on Magnetic Refrigeration at Room Temperature

Publication date:

2012

Document Version

Publisher's PDF, also known as Version of record

Link back to DTU Orbit

Citation (APA):

Olsen, U. L., Bahl, C., Engelbrecht, K., Nielsen, K. K., Tasaki, Y., Takahashi, H., \& Yasuda, Y. (2012). Modeling of In-vehicle Magnetic refrigeration. In Proceedings of the fifth IIF-IIR International Conference on Magnetic Refrigeration at Room Temperature: Thermag $\mathrm{V}$

\section{General rights}

Copyright and moral rights for the publications made accessible in the public portal are retained by the authors and/or other copyright owners and it is a condition of accessing publications that users recognise and abide by the legal requirements associated with these rights.

- Users may download and print one copy of any publication from the public portal for the purpose of private study or research.

- You may not further distribute the material or use it for any profit-making activity or commercial gain

- You may freely distribute the URL identifying the publication in the public portal 


\title{
Modeling of In-vehicle Magnetic refrigeration
}

\author{
${\text { U.L. } \operatorname{OLSEN}^{(a)}, \text { C. R. H. BAHL }}^{(a)}, K_{\text {ENGELBRECHT }}^{(a)}$, K.K. NIELSEN $^{(a)}$, \\ Y. TASAKI ${ }^{(b)}$, H. TAKAHASHI $^{(b)}$ and Y. YASUDA ${ }^{(b)}$ \\ (a) Department of Energy Conversion, \\ Technical University of Denmark - DTU, \\ DK-4000 Roskilde, Denmark \\ +45 4477 5842, ullu@dtu.dk \\ (b) Nissan Motor Co., Ltd. Nissan Research Center \\ 1 Natsushima-cho, Yokosuka-shi, Kanagawa, Japan \\ +81-46-867-5196, y-tasaki@mail.nissan.co.jp
}

\begin{abstract}
A high-performance magnetic refrigeration device is considered as a potential technology for invehicle air conditioners in electric vehicles. The high power consumption of a conventional air conditioner in an electric vehicle has considerable impacts on cruising distance. For this purpose the demands on cooling power density, temperature difference between hot and cold side, transient properties and COP, will be high.
\end{abstract}

\section{INTRODUCTION}

Numerical simulations have been performed to explore the feasibility of in-vehicle magnetic refrigeration. An ambitious goal of comparatively high cooling power density and large temperature difference between the hot and cold sides has been set. The goal has been deemed necessary to place magnetic refrigeration as a viable option for electrical vehicles. In order to reach the goal an open-minded parameter search has explored the limitations of multiple systems, both conceptual and well-established. One set of simulations has been made stretching the parameter space of a conventional AMR device (Bahl et al 2008) and another has been made considering a novel solid state approach (Tasaki et al. 2012). Extreme material properties have been invoked to fix performance boundaries and aid to find the most promising development paths. Both sets of simulations uses algorithms based on a 1D approach (Engelbrecht et al, 2005) employ the use of Curie temperature graded magnetocaloric materials stressing the importance of accurate control of the Curie temperature in order to employ multiple materials in reaching the goal. The main factors influencing the performance in both approaches have been studied and compared. The focus has been on variations of thermal conduction and thermal convection as it is recognized in the field to represent an important bottleneck (Kitanovski and Egolf, 2010).

The ambitious goal has been set to obtain cooling power at a temperature span of $60^{\circ} \mathrm{C}$. The high temperature span will ensure sufficient temperature difference between ambient temperature and heat exchangers to give cooling in extremely hot environments and still run the heat exchangers efficiently.

\section{MODEL}

The work presented in this paper models two different designs for a magnetic cooling device. Firstly model V, a conventional AMR design using parallel plate regenerators and an aqueous solution as heat transfer fluid. Secondly model D, a novel design proposed in Kitanovski and Egolf (2010) and further developed by Nissan (Tasaki et al. 2012) utilizing the conceptual properties of thermal switches to avoid the use of a heat transfer fluid.

For both models a graded MCM has been used. Since the study intends to explore and compare the nature of the two regenerator configurations the material properties have been taken from the MFT 
model (Petersen et al, 2008, Morrish, 1965). The high temperature difference makes a single material regenerator unfeasible (Nielsen et al, 2010). Instead of just using an arbitrary higher number of materials a perfectly graded MCM has been implemented. A similar approach was used by Bjørk et al. (2011) although with a $\Delta \mathrm{T}_{\mathrm{ad}}$ constant in temperature. In this study the material in each numerical node in the material was assigned a Curie temperature corresponding to its temperature. The temperature of a node was found from its position and a linear thermal profile between the heat exchangers. The temperatures of the hot and the cold heat exchangers are $308 \mathrm{~K}$ and $248 \mathrm{~K}$ respectively.

\subsection{Model V}

This model has the magnetocaloric material (MCM) in the form of parallel plates and water is used as the heat transfer fluid. The operation of the AMR cycle consists of 4 parts lasting a total time, $\tau$ : 1. The MCM is magnetized, 2. Hot blow, the fluid is pushed from the cold to the hot reservoir, 3. The MCM is demagnetized, 4. Cold blow, the fluid is pushed from the hot to the cold reservoir. Magnetization and Demagnetization lasts an equal time $\tau_{1}$. The two blows also last an equal time $\tau_{2}$. The length the fluid is pushed is characterized by its ratio to the length of the MCM.

The study has the aim of exploring the boundaries of performance. It is recognized that thermal contact to the heat transfer fluid plays an important role in the performance of an AMR device (Dragutinovic \& Baclic, 1998). In the pursuit of increasing the thermal contact the influence of the plate surface has attracted the attention of research (Ciofalo et al, 2000, Zhang et al. 2005, Engelbrecht et al, 2011, Šarlah et al, 2012). Several methods have been reported that could increase the heat transfer from the fluid to the walls of a pipe of travelling fluid. In this study such a "dream Pipe" effect has been generalized as an increase of the Nusselt number. In the model the Nusselt number is multiplied with the Dream pipe factor.

The operation can be described by the following parameters:

$\begin{array}{ll}\text { Magnetic Field: } & 1.37 \mathrm{~T} \text { (corresponding to a maximal } \Delta \mathrm{T}_{\mathrm{ad}} \approx 5 \mathrm{~K} \text { ) } \\ \text { Plate thickness: } & 50,150,300,500 \mu \mathrm{m} \\ \text { Plate length: } & 12,24,36 \mathrm{~cm} \\ \text { Channel thickness: } & \text { the same as the plate thickness } \\ \text { Ratio Stroke length to plate length: } & 0.2,0.4,0.6,0.8,0.1,1.2 \\ \text { Cycle Frequency: } 1 / \tau & 50,20,10,5,2,1 \mathrm{~Hz} \\ \text { Relative stroke time } \tau_{1} / \tau_{2}: & 0.3,0.4,0.5,0.7,0.9 \\ \text { Dream pipe factor } & 1,2,4,10\end{array}$

\subsection{Model D}

The second model is further described in Tasaki et al (2012). A schematic is shown in Figure 1. This model relies on a concept of thermal switches (TS) to control the direction of the heat transfer. The cycle for this model consist of alternating magnetization of every other MCM segment. The magnetic field is applied for half a cycle with a linear ramping time lasting $5 \%$ of the cycle time. For a magnetized segment the TS towards the hot side is open while the TS towards the cold side is closed. The opposite is true for a demagnetized segment. 


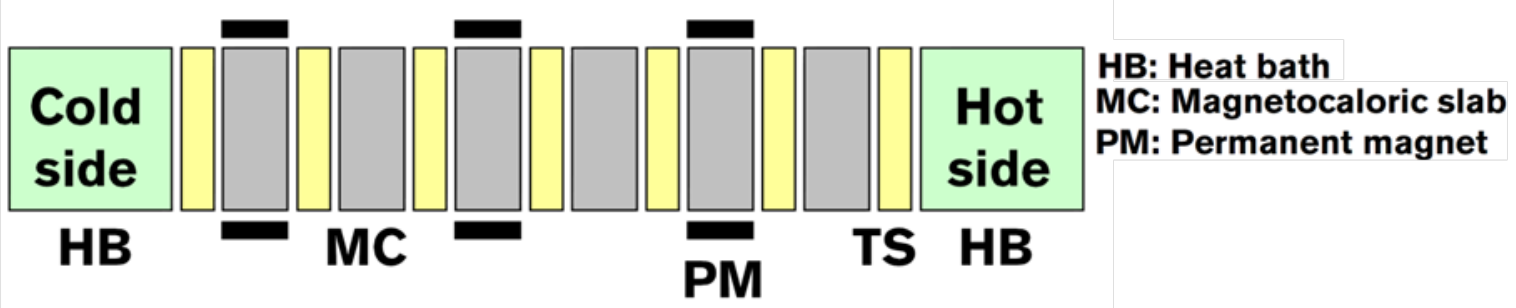

Figure 1 Schematic of an AMR device utilizing thermal switches.

The operation can be characterized by the following parameters:

Segments length

TS length

TS thermal conductivity

MCM thermal conductivity

Cycle Frequency: $1 / \tau$
$0.3,0.5,1,2,3,5,10,20 \mathrm{~mm}$

0.2 x Segments length

$100,200,400 \mathrm{~W} / \mathrm{K} / \mathrm{m}$

$10,100,200,400 \mathrm{~W} / \mathrm{K} / \mathrm{m}$

200, 100, 50, 20, $10 \mathrm{~Hz}$

Furthermore the total regenerator consist of 24 segments each separated by a TS. The TS has been implemented with either no specific heat or a constant specific heat of 100 or $300 \mathrm{~J} / \mathrm{K} / \mathrm{kg}$.

\section{RESULTS}

In both models a temperature span of $60 \mathrm{~K}$ has been set, as discussed above, and the resulting cooling power is calculated. As expected the high performance goals limit the number of configurations that result in a positive cooling power. In the following only results with a positive cooling power are reported. Since the size of the device is an evaluation parameter in the study the cooling power is reported as a function of the volume of the device. For model $\mathrm{V}$ the volume is taken as the volume of the MCM and the volume of the fluid channels between the MCM plates. For model D the volume is taken as the volume of the MCM and the volume of the TS's. In both cases heat exchangers, magnets and auxiliary components have been left out for clarity of the investigated subject. A study of the collective system has previously been performed for an AMR like the fluid model (Bjørk et al, 2011).

\subsection{Model V}

The "Dream pipe" factor is observed to have a pronounced effect on performance. In Figure 2 the volumetric cooling power is shown as a function of frequency for 4 different parameters of the "Dream pipe" factor in the fluid model. The best configuration of the remaining parameters is used for each data point. For slow cycles the cooling power increases with frequency. Faster cycles do not allow sufficient time to transfer all the thermal energy between fluid and the MCM. For

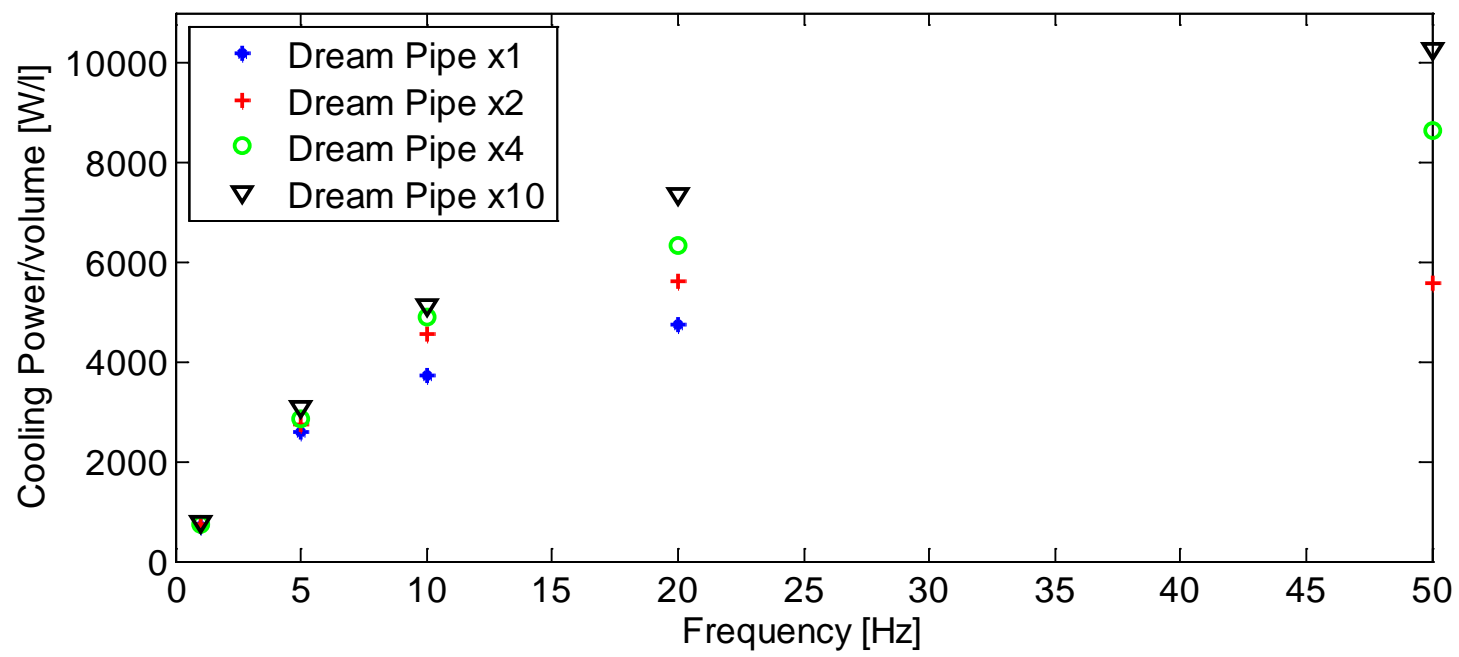

Figure 2 Cooling effect as a function of cycle frequency. The frequency axis is logarithmic and only the best performing configurations for each frequency is shown for better clarity. 
configurations with no topology optimization towards heat transfer (Dream pipe $\mathrm{x} 1$ ) a maximum cooling power is achieved for cycle frequencies between 10 and $20 \mathrm{~Hz}$. As the heat transfer is increased through the "Dream pipe" effect the linear power increase continues at higher frequencies.

Not shown in the figure is the effect of the regenerator length. Nielsen has shown (2012) that for $500 \mu \mathrm{m}$ plates longer regenerators perform better than short. For $50 \mu \mathrm{m}$ plates the volumetric cooling power decrease with the length of the plates at $50 \mathrm{~Hz}$ for the studied lengths. The ratio of thermal backflow between heat reservoirs and the heat transfer to the fluid is proportional to plate thickness making the optimal length increase with the thickness of the MCM plates.

The coefficient of performance (COP) is calculated as $\mathrm{COP}=\mathrm{Q}_{\mathrm{c}} / \mathrm{W}, \mathrm{W}$ is the work input to the regenerator, $\mathrm{Q}_{\mathrm{c}}$ is the heat transferred to the cold reservoir. This is used as a figure of merit of the cycle efficiency. The Carnot efficiency is the theoretical maximum of the efficiency and is given by the temperatures of the hot and the cold heat exchanger. For the present study the Carnot efficiency is 4.1 .

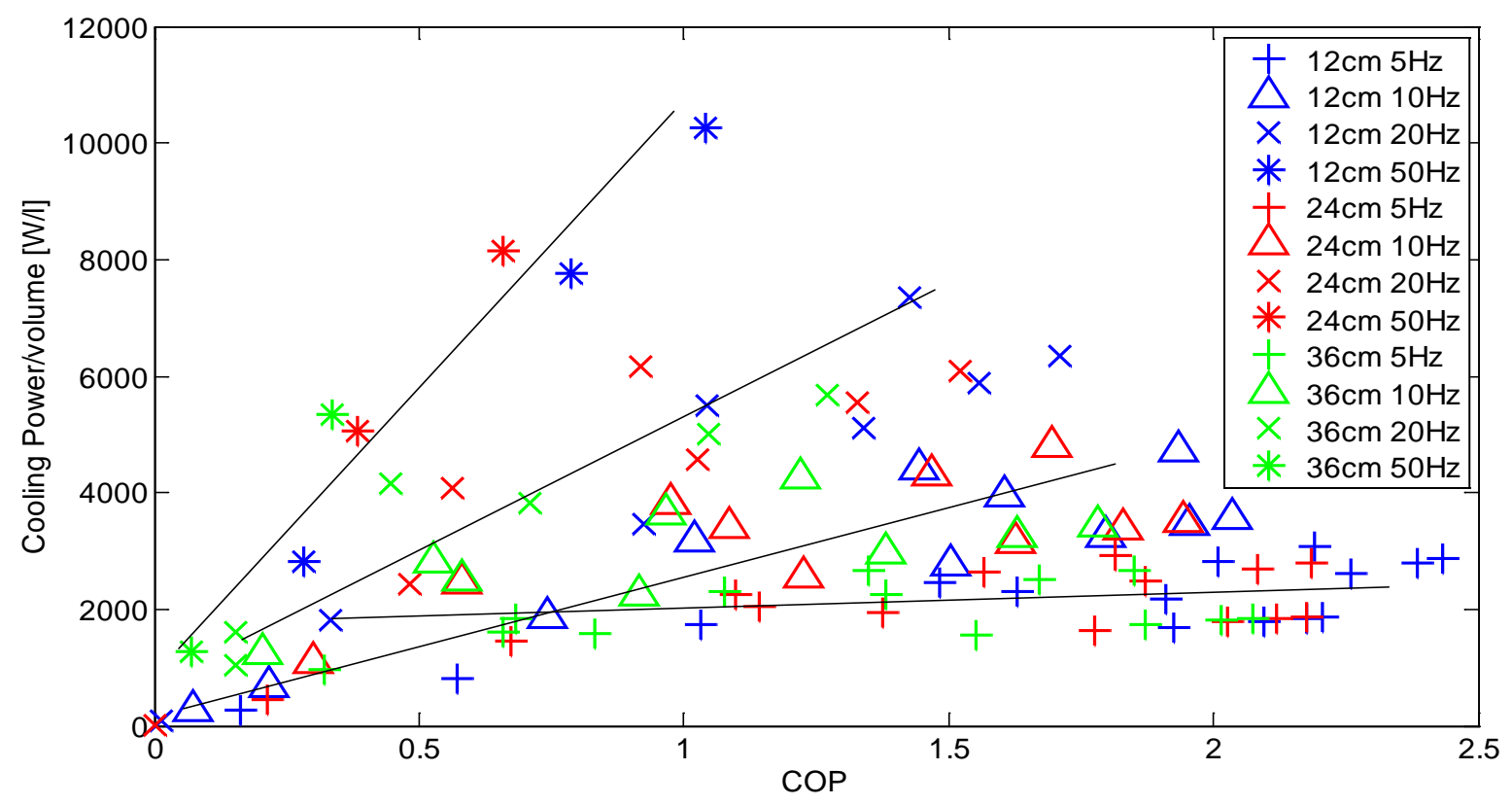

Figure 3 Cooling power vs. COP for the Fluid model for $50 \mu \mathrm{m}$ plates. The lines serves as guides to the eye following concentrations of points with the same frequency.

In Figure 3 the configurations with the highest cooling power is plotted as a function of the COP. Since the highest cooling power is obtained for $50 \mu \mathrm{m}$ plates only these configurations are shown in the graph. The configurations align close to linearly with frequency. A higher frequency has a higher cooling power as a function of COP. 


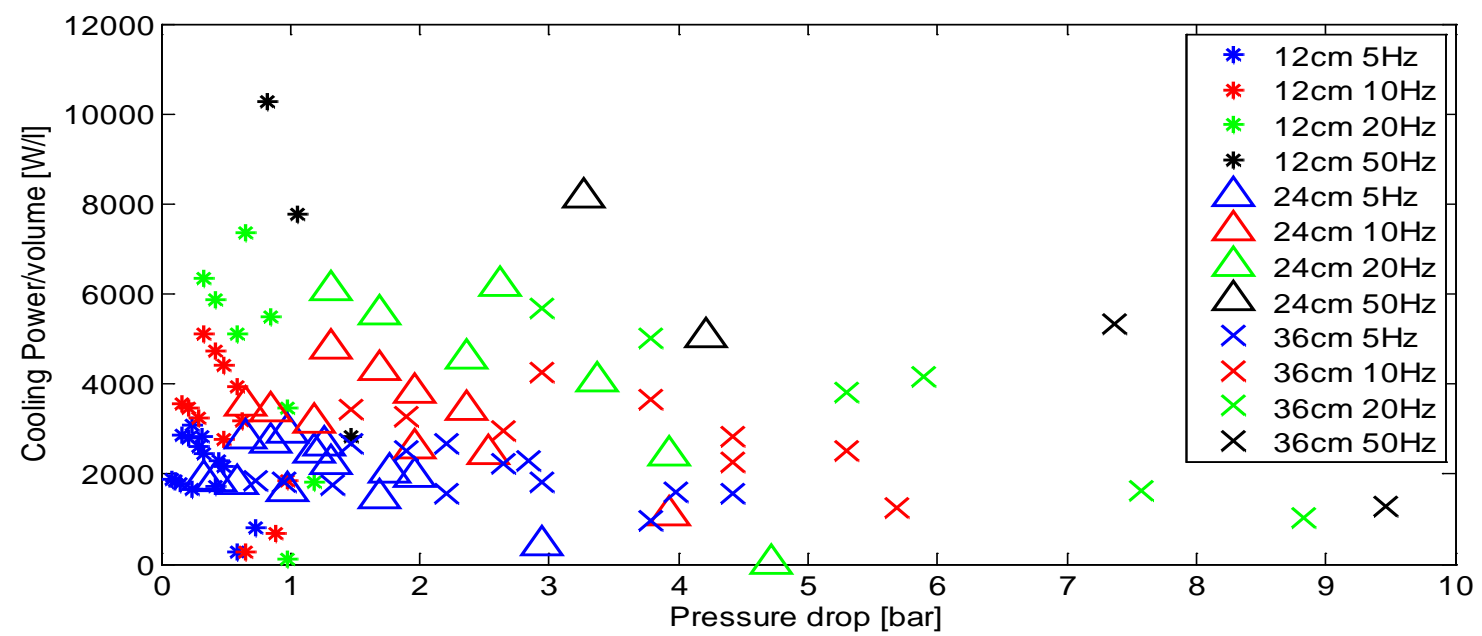

Figure 4 Cooling power as a function of pressure drop for $50 \mu \mathrm{m}$ plates. The pressure increases with the length of the regenerator as well as the cycle frequency.

Work enters the system in two ways:

- Magnetic work from moving the magnet relative to the MCM.

- Pump work from moving the fluid relative to the MCM.

The heat transfer increase gained from using thinner plates and channels occurs at the expense of a higher pressure drop and increased pump work. In Figure 4 the cooling power is shown as a function of pressure drop. Only points for $50 \mu \mathrm{m}$ channels are shown as for all the simulations with $150 \mu \mathrm{m}, 300 \mu \mathrm{m}$ and $500 \mu \mathrm{m}$ channels the pressure drop is negligible, below 0.2 bar. From the figure the influence of regenerator length and frequency is shown. In this context the "Dream pipe" effect is implemented without influencing the pressure drop. For all cases we have studied the "Dream pipe" effect will influence the resistance against the fluid as suggested from the Reynolds analogy (Eckert and Drake, 1971), but an exact number will depend on the implementation.

\subsection{Model D}

The operation of model D is much clearer since fewer parameters govern the performance of the model. Firstly, the effects of the changing material properties are examined.

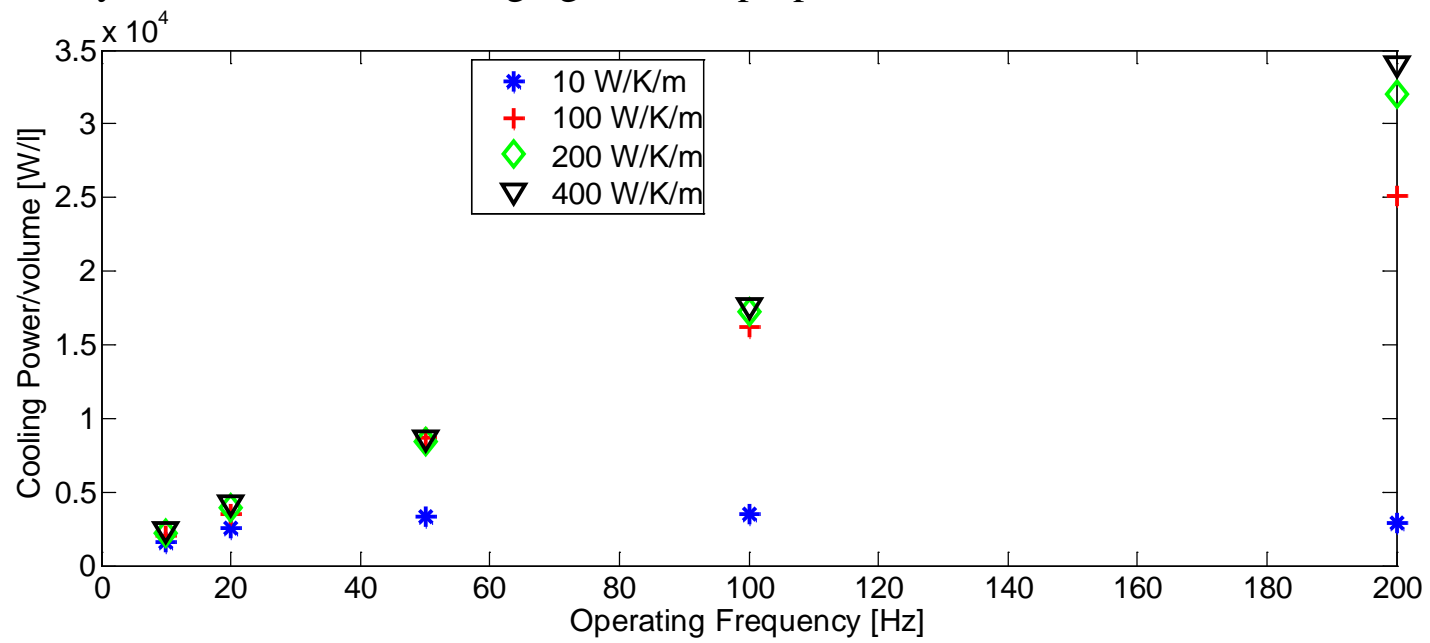

Figure 5 Cooling power as a function of frequency for model D. Performance is shown for variations of the thermal conductivity of MFT gadolinium. Only the best performing configurations for each frequency is shown.

The thermal conductivity of the MCM is varied from an initial value of $10 \mathrm{~W} / \mathrm{K} / \mathrm{m}$ to $100 \mathrm{~W} / \mathrm{K} / \mathrm{m}$, $200 \mathrm{~W} / \mathrm{K} / \mathrm{m}$ and $400 \mathrm{~W} / \mathrm{K} / \mathrm{m}$. These are not realistic values for gadolinium but as written above, the current study is an exploration of the performance limits and not of a specific material. Figure 5 
shows that $10 \mathrm{~W} / \mathrm{K} / \mathrm{m}$ represents the bottleneck for performance from cycle frequencies of $20 \mathrm{~Hz}$. When the thermal conductivity is increased performance scales linearly with the cycle frequency.

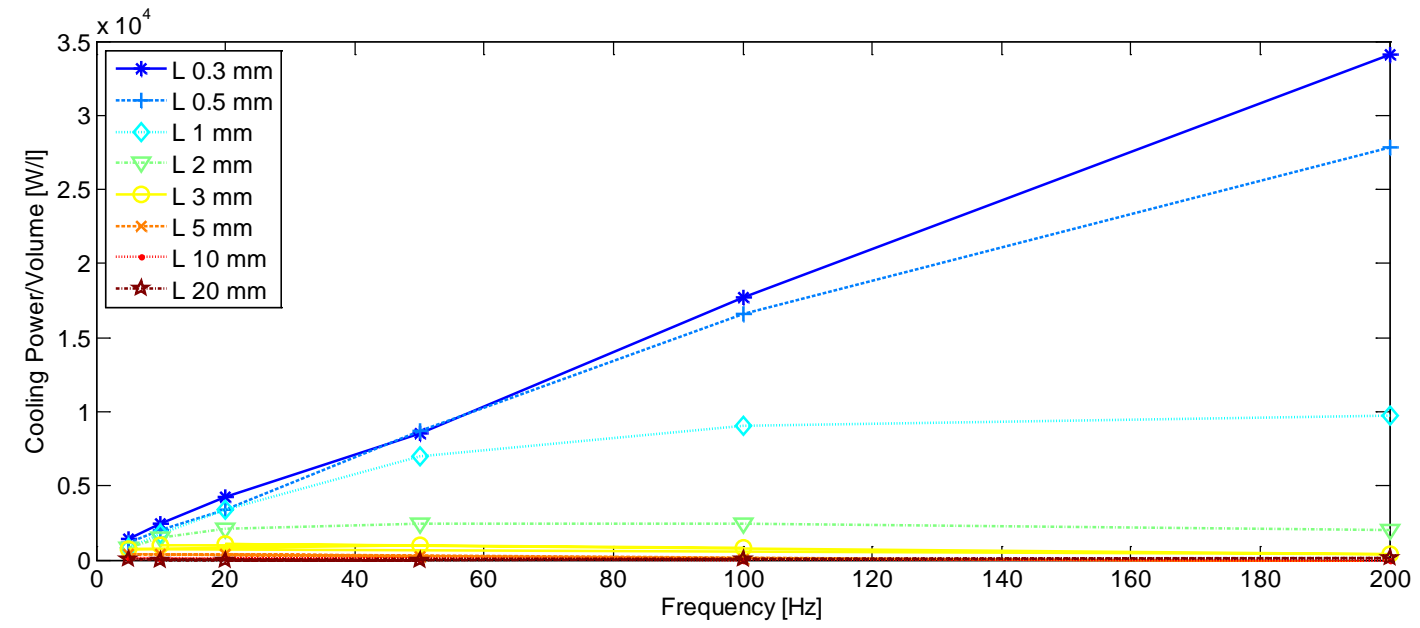

Figure 6 Cooling power as a function of frequency. The peak of the cooling power occurs at lower frequencies for the configurations with the thickest segments. The data points of $5 \mathrm{~mm}, 10 \mathrm{~mm}$ and $20 \mathrm{~mm}$ segments coincide at this scale.

The influence of geometry is shown in Figure 6. Only the parameter set with the best performance for each frequency is shown. Short MCM segments allow the heat to be transferred faster and the performance increases linearly for all frequencies in the examined range. It shows that the available thermal mass undergoing MCE is not a limitation on performance even for the most accelerated heat transfer conditions.

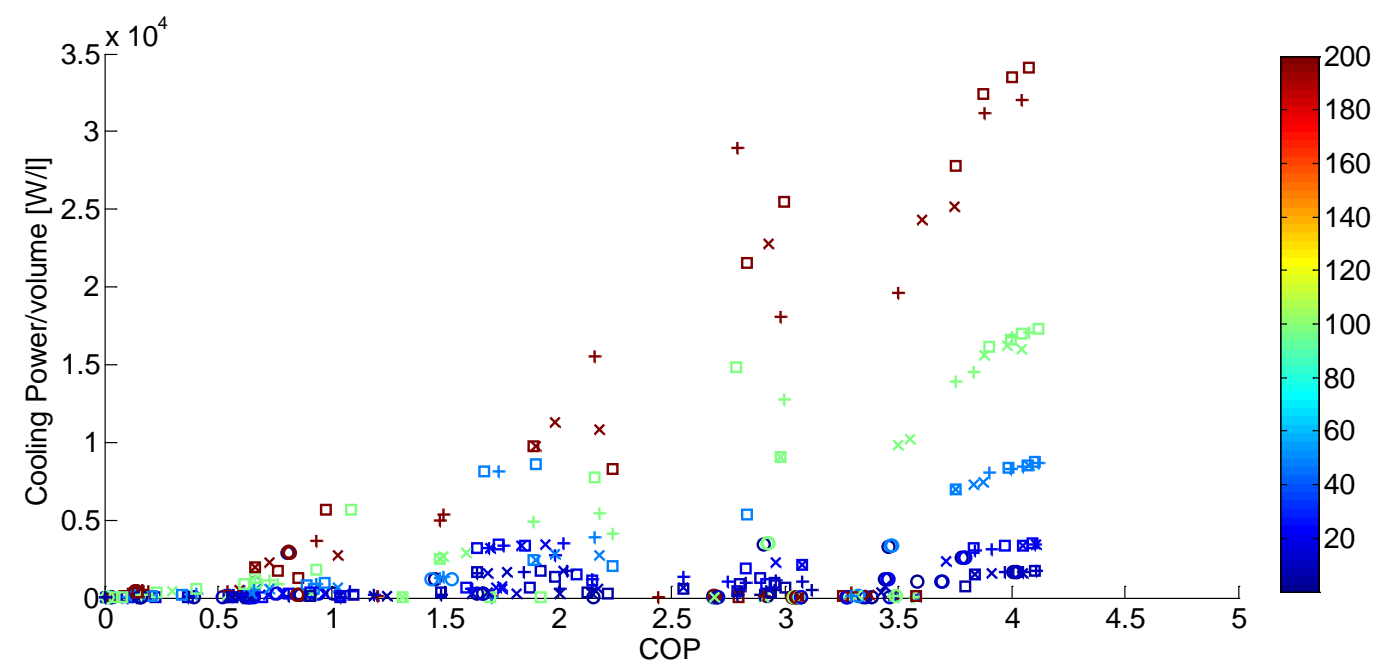

Figure 7 Cooling power as a function of COP. The data comes from the D model using different thermal conductivities for the MCM: $10\left({ }^{\circ}\right), 100(\times), 200(+)$ and $400(\square) \mathrm{W} / \mathrm{m}-\mathrm{K}$. The color represents the cycle frequency. Colorbar unit is Hz.

The COP of model D is shown in Figure 7. The cooling power is influenced by the thermal conductivity, the cycle frequency and the regenerator length. COP for model D at the maximal value of cooling power are higher than COP at the maximum cooling power of model $\mathrm{V}$.

\subsection{Thermodynamical Comparison}

Model D and the model V work thermodynamically very differently. In Figure 8 data from each of the two models are shown in a T-S diagram. The frequency was $20 \mathrm{~Hz}$ in both models otherwise dreampipe factor is 10 Relative stroke length is 0.2 relative stroke time is 0.5 and total length is $12 \mathrm{~cm}$ for V model For D model the MCM and thermal switch conductivity is both $400 \mathrm{~W} / \mathrm{m} / \mathrm{K}$ and segments length $0.3 \mathrm{~mm}$. Cycles are shown for a few regularly spaced nodes that are calculated in 
the algorithm. The role of the heat transfer fluid is not included in the T-S diagram which only shows the values of the MCM.

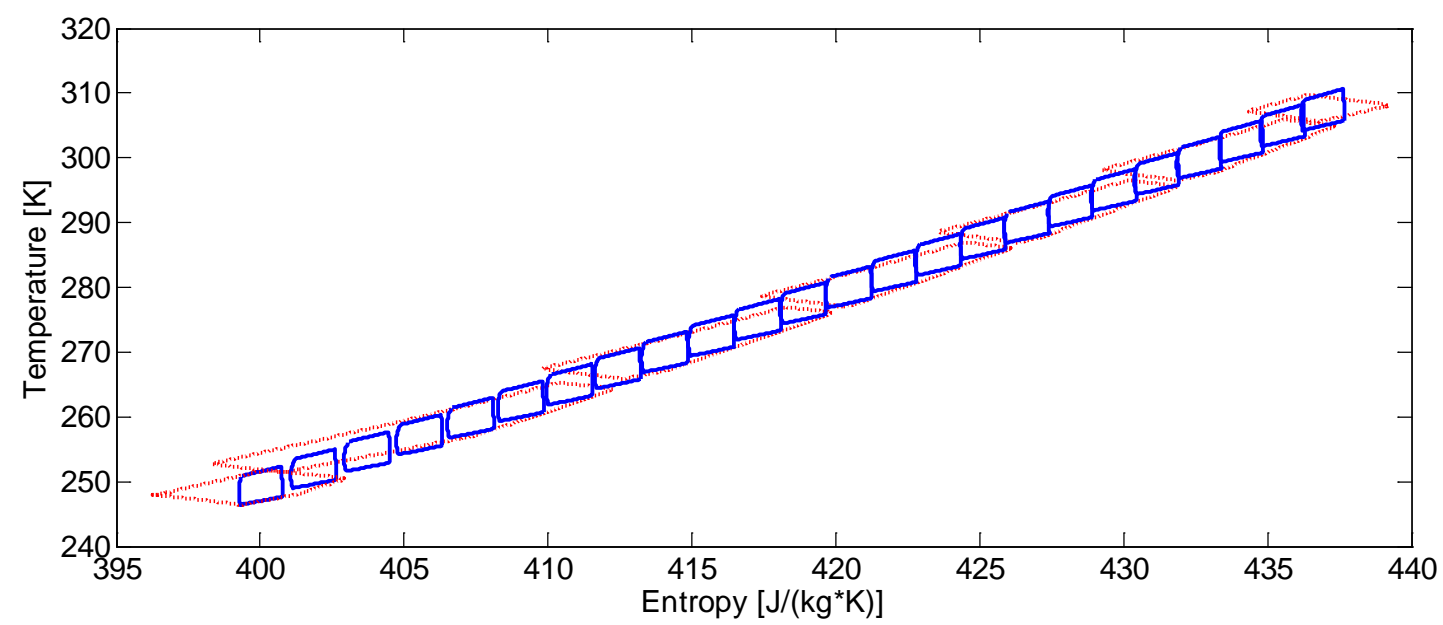

Figure 8 TS-diagram for the two models. Red curves are from the model V. Blue is model D. Not all the calculated nodes are shown to avoid overlap and increase clarity.

For an ideal reversible cycle the T-S diagrams can be used to estimate the heat input and output as well as the required work. The two models do not have reversible cycles but in comparison the TS diagrams still provide some insight. Collectively the cycles cover almost the same area. This means the work per mass is approximately the same. However the mass involved in the work are very different for the two models. The total volumetric work is $915 \mathrm{~W} / \mathrm{l}$ and $825 \mathrm{~W} / \mathrm{l}$ from the $\mathrm{V}$ and the $\mathrm{D}$ model, respectively. The heat output $\mathrm{Q}_{\mathrm{c}}$ is found as the area underneath the last node for the $\mathrm{V}$ model and the last segment for the D model. Q are $2167 \mathrm{~W} / \mathrm{l}$ and $3365 \mathrm{~W} / \mathrm{l}$ for the V and the D model respectively. Thus the COPs can be found as 2.4 and 4.1 respectively. These numbers and the numbers calculated by the algorithm are summarized in the table below:

\begin{tabular}{|l|c|c|c|c|c|c|}
\cline { 2 - 7 } \multicolumn{1}{c|}{} & $\begin{array}{c}\mathrm{Q}_{\mathrm{c}} \\
{[\mathrm{W} / \mathrm{l}]}\end{array}$ & $\begin{array}{c}\mathrm{Q}_{\mathrm{c}} \text { model } \\
{[\mathrm{W} / \mathrm{l}]}\end{array}$ & $\begin{array}{c}\text { Work } \\
{[\mathrm{W} / \mathrm{l}]}\end{array}$ & $\begin{array}{c}\text { Work model } \\
{[\mathrm{W} / \mathrm{l}]}\end{array}$ & COP & COP model \\
\hline Model D & 3365 & 3345 & 825 & 828 & 4.1 & 4.0 \\
\hline Model V & 2167 & 5833 & 915 & 2917 & 2.4 & 2.0 \\
\hline
\end{tabular}

There is a large discrepancy between the numbers from the T-S diagram and from the algorithm for model V. However the fluid is not incorporated in the T-S diagram. Since the fluid plays a large part in the transport of heat this explain the difference in work and heat output. For the efficiencies reported elsewhere in this paper the work of the pump is included in the COP but here it is omitted to directly compare with T-S diagram. A small difference is found for the D model between T-S diagram and algorithm. The heat transfers between segments in the D model are not reversible and will give efficiency losses. We expect most of the difference is due to these losses.

\section{CONCLUSION}

We have presented results from a numerical study of two very different models for active magnetic refrigeration. Firstly a conventional fluid model utilizing 50 $\mathrm{\mu m}$ plates of a perfectly graded Gd-like material. This model had enhanced heat transfer between MCM and fluid by means of a "Dream pipe" effect. This effect was implemented by a multiplied factor to the Nusselt number. Maximum cooling power for this model is $10 \mathrm{~kW} / \mathrm{l}$. Secondly a conceptual model was evaluated. The model uses thermal switches to control the heat flow in the MCM thus dispensing with the heat transfer 
fluid. In this model the thermal conductivity of the MCM was increased between 10 and 400 $\mathrm{J} / \mathrm{kg} / \mathrm{K}$. The maximum cooling power for this model is $34 \mathrm{~kW} / \mathrm{l}$.

The intention of the study has been an open minded exploration of parameters. A number of challenges exist in the realization of a device utilizing thermal switches:

- Magnetizing very thin segments.

- Obtaining a sufficient high ratio of heat conduction in the ON and OFF state of the thermal switches

- Obtaining adequate thermal transfer in the MCM. Unlike in the fluid model heat transfer through the MCM is desirable and necessary.

The novel method of controlling the heat flow direction has a distinct effect on the COP. The disposal of heat transfer fluid removes many loss terms. If thermal switches can be produced with a high dynamic range of heat conduction, this model has very high applicable potential.

The "Dream pipe" increase in thermal transfer from a solid MCM to a heat transfer fluid will likely have a corresponding increase in pressure drop. However with no additional improvements and without a prohibitive pressure drop the accurate production of $50 \mu \mathrm{m}$ MCM plates will give a high volumetric cooling power even with $60 \mathrm{~K}$ temperature span. 
Fifth IIF-IIR International Conference on Magnetic Refrigeration at Room Temperature, Thermag V

Grenoble, France, 17-20 September 2012

\section{REFERENCES}

[1] Bahl C. R. H, Petersen T. F, Pryds N, Smith A, 2008, A versatile magnetic refrigeration test device, Rev. Sci. Instum, 79: 093906

[2] Bjørk R, Smith A, Bahl C. R. H, Pryds N, 2011, Determining the minimum mass and cost of a magnetic refrigerator, Int. J. Refrig. 34(8): 1805-1816.

[3] Ciofalo M, Di Piazza I, Stasiek J. A, 2000, Investigation of flow and heat transfer in corrugatedundulated plate heat exchangers, Heat and Mass Transfer 36 (5): 449-462

[4] Dragutinovic, G. D, Baclic B. S, 1998, Operation of Counterflow Regenerators, Computational Mechanics Inc., Billerica, MA

[5] Eckert E. R. G, Drake R. M, 1971, Analysis of Heat and Mass Transfer, McGraw-Hill, Columbus OH

[6] Engelbrecht K. L, Nellis G. F, Klein S. A, 2005, A numerical model of an active magnetic regenerator refrigeration system, 9: 471-480.

[7] Engelbrecht K, Nielsen K. K, Pryds N, 2011, An experimental study of passive regenerator geometries Int. J. Refrig. 34: 1817-1822

[8] Kitanovski A, Egolf P. W, 2010, Innovative ideas for future research on magneto caloric technologies, Int. J. Refrig. 33: 449-464

[9] Morrish, A. H, 1965, The Physical Principles of Magnetism, Wiley, New York, NY

[10] Nielsen K. K, Bahl C. R. H, Engelbrecht K, Smith A, Pryds N, Hattel J, 2010, Numerical modeling of graded active magnetic regenerators, Fourth IIF-IIR International Conference on Magnetic Refrigeration at Room Temperature

[11] Nielsen K. K, Engelbrecht K, 2012, The influence of the solid thermal conductivity on active magnetic regenerators, Journal of Physics D: Applied Physics, accepted.

[12] Petersen T F, Pryds N, Smith A, Hattel J, Schmidt H, Knudsen H. 2008, Two-dimensional mathematical model of a reciprocating room temperature active magnetic regenerator. Int. J. Refrig. 31: 432.

[13] Šarlah A, Tušek J, Poredoš A, 2012, Comparison of Thermo-Hydraulic Properties of Heat

Regenerators Applicable to Active Magnetic Refrigerators, Journal of Mechanical Engineering 58(1): 16-22

[14] Tasaki Y, Takahashi H, Yasuda Y, Okamura T, Ito K, 2012, A study on the fundamental heat transport potential of an in-vehicle magnetic refrigerator, Thermag V. 